\title{
RANCANG BANGUN APLIKASI SISTEM MONITORING PERTUMBUHAN ANAK SEBAGAI ALAT DETEKSI PERTUMBUHAN
}

\author{
Julizal $^{1}$, Lukman ${ }^{2}$, Imam Sunoto ${ }^{3}$ \\ Program Studi Informatika, Universitas Indraprasta PGRI \\ julizal.ram@gmail.com, 1kmnaja51@gmail.com, raidersimam@gmail.com
}

Submitted May 15, 2019; Revised July 21, 2019; Accepted July 27, 2019

\begin{abstract}
Abstrak
Pada umumnya para anggota Posyandu dan Bidan Klinik masih memiliki pengetahuan yang kurang mengenai pemantauan perkembangan anak terutama mengenai gangguan perkembangan dan pengetahuan terhadap gangguan atau permasalahan pertumbuhan terhadap anak secara cepat. Tujuan penelitian adalah membuat program aplikasi pendeteksi perkembangan anak agar mudah dalam mengelolah data serta membuat laporan menjadi lebih cepat dan tepat. Klinik mengenai cara pemantauan perkembangan anak secara sederhana melalui pemanfatan Program Aplikasi berbasis desktop dengan bahasa pemrograman java dalam pengolahan pertumbuhan anak atau kartu pertumbuhan anak sebagai aplikasi pemantauan permasalahan atau penyimpangan pertumbuhan anak. Model dalam pemecahan masalah ini yaitu pendekatan pendidikan masyarakat, dan metode yang digunakan adalah rancang bangun program aplikasi berbasis desktop dengan bahasa pemrograman java dalam pengolahan lembar perkembangan anak. Pengisian lembar perkembangan bayi balita dapat terlihat hasil kembang anak secara cepat meliputi pemantauan permasalahan atau penyimpangan pertumbuhan anak apabila menggunakan program aplikasi. Kesimpulanya bagaimana cara membuat suatu program aplikasi sebagai pendeteksi kembang anak secara cepat dan tepat. Namun demikian masih diperlukan monitoring dan bimbingan lanjutan agar para ibu kader Posyandu dan bidan Klinik dapat melaksanakan kegiatan pemantauan perkembangan anak dengan menggunakan program aplikasi secara mandiri dan berkesinambungan.
\end{abstract}

Kata Kunci: Katu kembang, Posyandu, Rancang bangun, Aplikasi.

\begin{abstract}
In general Posyandu and Clinical Midwives cadres still have insufficient knowledge about matters relating to child development, especially regarding developmental disorders and simple ways to quickly detect developmental disorders or deviations in children. The purpose of research is to create a child development detection application program to improve the knowledge, understanding and skills of Posyandu cadres and Clinical midwives on how to monitor child development simply through the use of desktop-based Application Program with java programming language in processing the Child Development Card or the development sheet for infants and toddlers as a means of early detection of disorders or deviations in child development. The approach model used for solving this problem is the community education approach, and the method used is the design of a desktop-based application program with the Java programming language in processing the child's development sheet. Filling out the development sheet for a toddler can quickly see the child's development results including early detection of disturbances or deviations in child development when using an application program. The conclusion is how to make an application program as a detector of children's growth quickly and precisely. However, further monitoring and guidance is still needed so that Posyandu cadres and Clinic midwives can carry out monitoring activities on child development by using the application program independently and continuously.
\end{abstract}

Keywords: Development, Posyandu, Design, Application.

\section{PENDAHULUAN}

Istilah tumbuh kembang anak yaitu perkembangan anak berhubungan dengan segala hal mengenai perkembangan anak baik itu tinggi ,lebar dan perkembangan organ lainnya. Perkembangan lebih menitikberatkan pada aspek perubahan bentuk atau fungsi pematangan organ 
tubuh individu, termasuk perubahan aspek sosial atau emosional akibat pengaruh lingkungan [1].

Perkembangan anak meliputi kepada aspek perubahan bentuk atau fungsi pematangan organ tubuh anak, termasuk perubahan aspek sosial atau emosional akibat pengaruh lingkungan [1]. Pada lingkungan masyarakat pertama yang di lakukan dalam kesehatan anak adalah dengan mendatangi posyandu terdekat, dengan cara mendaftar pada posyandu tersebut dan mendapatkan kartu posyandu. Proses perkembangan anak yang maksimal tidak hanya meliputi oleh aspek-aspek pertumbuhan, tetapi harus juga memperhatikan aspek perkembangan seperti perkembangan gerak, berbicara, berjalan dan lainnya.

Monitoring terhadap aspek perkembangan anak belum banyak dikenal umum di masyarakat Sebagian umum masyarakat masih belum paham terhadap masalah dalam aspek perkembangan anak agar bisa dimonitor secara dini untuk meminimalkan efek negatif terhadap permasalahan tersebut. Hal ini dipengaruhi oleh pendidikan dan pengetahuan yang masih minim tentang pentingnya monitoring perkembangan anak, sehingga perlu dikelola oleh program aplikasi berbasis komputer, sehingga didapatkan informasi tentang perkembangan anak dalam mendeteksi perkembangan anak secara cepat dan tepat.

Di Posyandu Bougenvile Depok, masih banyak didapati keluarga yang mempunyai bayi dan balita kurang mengetahui informasi mengenai perkembangan anaknya. Di Posyandu Bougenvile Depok, kurangnya pengetahuan ibu-ibu mengenai gejala-gejala pada bayi dan balita mereka.terutama pada respek dan respon bayi dan tumbuh kembangnya.

Beberapa masyarakat umum terutama orangtua kurang pemahaman mengenai perkembangan anak secara normal maupun permasalahan dalam perkembangan anak, serta ketidakpahaman mengenai cara penggunaan program aplikasi untuk memonitor terhadap perkembangan terhadap anak, secara cepat dan tepat.

Sistem Informasi adalah sekumpulan data apa pun dari orang-orang, berupa hardware, software, jaringan komunikasi, dan sumber daya data dengan mengumpulkan, mengubah, dan menyebarkan informasi dalam sebuah organisasi. Selain itu, pengertian dari sistem informasi merupakan sekelompok elemen yang saling berhubungan atau berinteraksi hingga membentuk satu kesatuan [2].

Lembar Perkembangan Anak atau lembar perkembangan bayi balita merupakan alat sederhana yang masih bersifat manual untuk deteksi dini penyimpangan atau gangguan perkembangan anak. Apabila dengan penggunaan program aplikasi pendeteksian kembang anak berdasarkan data dari lembar monitoring perkembangan anak dan balita dapat diketahui hasilnya dengan tepat dan akurat serta tidak berdasarkan perasaan. Program aplikasi ini perlu disosialisasikan, agar pemanfaatannya oleh masyarakat umum yang langsung berhubungan secara dekat dengan anak bisa lebih baik, sehingga pemantauan pertumbuhan perkembangan anak dapat dilaksanakan secara cepat dan optimal. Diharapkan dapat menunjang keberhasilan masa depan anak dan kebahagiaan keluarga.

Proses pertumbuhan dan perkembangan anak meliputi seluruh proses kejadian semenjak terjadi pembuahan sampai masa dewasa. Ciri pertumbuhan dan perkembangan yang utama adalah dalam masa tertentu terdapat masa percepatan dan masa perlambatan, serta laju pertumbuhan dan perkembangan yang berlainan di antara organ tubuh manusia. Pertumbuhan dan perkembangan biasanya merangkul dua kejadian yang sifatnya berbeda tetapi 
saling berkaitan dan sulit dipisahkan, yaitu pertumbuhan dan perkembangan. Pertumbuhan berhubungan pada perubahan dalam jumlah, besar, size atau ruang tingkat sel, organ, maupun sendiri. Pertumbuhan lebih pada ciri perubahan bentuk atau manfaat pematangan bagian tubuh orang, termasuk perubahan masyarakat atau gejolak hati akibat dampak pemungkinan [1].

Proses pertumbuhan mempunyai dampak terhadap aspek fisik, sedangkan proses perkembangan berkaitan dengan fungsi pematangan intelektual dan emosional pada manusia. Pertumbuhan memiliki sifat-sifat contoh: perubahan size, perubahan ukuran, hilangnya dahulu, dan munculnya karakter baru. Sedangkan perkembangan memiliki karakter seperti: berhubungan dengan perkembangan, mempunyai bentuk yang konstan, mempunyai tahapan yang sekuensial, mempunyai kecepatan yang berbeda, serta berhubungan dengan perkembangan [3].

Pemantauan perkembangan anak sangat penting, karena dengan pemantauan yang benar bisa dilakukan deteksi dini kelainan pada anak. Tekanan bisa dilaksanakan secara dini dan tumbuh kembang anak dapat lebih maksimal sesuai dengan kemampuan genetiknya [5].

Perkembangan seorang anak dapat dilakukan dengan cara berkonsultasi kepada petugas kesehatan yang perkaitan dengan anak yaitu dokter anak.Akan tetapi hal ini tidak bisa dilakukan secara berkala karena keterbatasan waktu dan kesibukan para orang tua dalam memenuhi kebutuhan.

Pemantauan perkembangan anak akan sangat bermanfaat apabila warga sekitar, serta teman- teman anak, dalam hal ini bunda,Perawat, dan keluarga memiliki ilmu yang baik tentang perkembangan anak. Disamping itu peninjauan gangguan perkembangan balita juga dapat dilakukan oleh saudara- saudara terdekat, dan untuk mendukung langkah- langkah peninjauan ini diharapkan suatu aplikasi sederhana dan mudah dipahami oleh orangtua sehingga dapat membantu.

Lembar Perkembangan Anak merupakan alat yang dapat dimanfaatkan sebagai centang dan sekaligus sebagai alat transmisi dalam mengolah perkembangan anak, dari dan untuk keluarga dalam masyarakat. Yang paling utama adalah untuk mewadahi hubungan antara bunda dengan anak. Di dalam Lembar Perkembangan Anak dirapikan beberapa pekerjaan perkembangan anak yang dilandasi pada ciri-ciri perkembangan, seperti: motorik kasar, motorik halus, komunikasi pasif, komunikasi aktif, kecerdasan dan kemampuan sosialisasi [5].

Pada lembar perkembangan anak ini juga disajikan petunjuk-petunjuk sederhana bagi ibu atau pengasuh dalam menuntun anak untuk memaksimalkan potensi perkembangan anak. Lembar Perkembangan Anak dapat dimanfaatkan untuk meninjau perkembangan anak secara berjenjang setiap bulan diawali dari nol sampai tujuh puluh dua bulan. dengan pemantauan yang bertahap dan berkesinambungan maka deteksi permasalahan yang dialami anak bisa dilakukan lebih awal dan cepat. Keberhasilan dalam penerapan program aplikasi pendeteksian kembang anak berdasarkan data dari lembar perkembangan anak dan balita dapat diketahui hasilnya dengan cepat dan tepat.

Berdasarkan uraian di atas, maka perlu adanya rancang bangun aplikasi untuk deteksi dini gangguan perkembangan dengan menggunakan pengolahan Lembar perkembangan anak dan balita. Serta bagaimana memotivasi para kader Posyandu dan bidan Klinik serta ibu-ibu yang memiliki bayi atau balita untuk memanfaatkan program aplikasi pendeteksian kembang anak berdasarkan 
monitoring lembar perkembangan anak dan balita secara mandiri dan berkesinambungan.

Tujuan dari penelitian ini adalah membuat rancang bangun aplikasi untuk pemantauan monitoring perkembangan dengan menggunakan pengolahan Lembar Perkembangan balita, sehingga diperoleh hasil yang cepat dan tepat serta memberikan informasi atau pengetahuan, dan sekaligus keterampilan kepada masyarakat terutama ibu-ibu, kader Posyandu dan bidan Klinik untuk dapat melakukan monitoring pertumbuhan dan perkembangan anak dan mendeteksi penyimpangan perkembangan secara dini.

Manfaat dari penelitian ini adalah diharapkan masyarakat terutama orangtua bisa lebih mudah memonitor pertumbuhan dan perkembangan anak mereka secara mandiri dan berkesinambungan, serta dapat melakukan monitoring pertumbuhan dan perkembangan pada anak yaitu dengan penggunaan program aplikasi yang telah dibangun sebagai alat deteksi. Selain itu diharapkan dapat memberi manfaat yang lebih luas dalam membantu program pemerintah di bidang pelayanan kesehatan dan pendidikan khususnya tentang monitoring pertumbuhan dan perkembangan anak agar setiap anak dapat tumbuh dan berkembang secara maksimal.

\section{METODE PENELITIAN}

Metode penelitian yang digunakan untuk melakukan program aplikasi sebagai pendeteksi kembang anak secara cepat dan tepat adalah dengan menggunakan model prototype sebagai metode pengembangan perangkat lunak (software). Model pengembangan perangkat lunak dengan model prototype ini akan menghasilkan sebuah aplikasi dalam bentuk prototype sebelum aplikasi tersebut memasuki tahap design. Dalam fase ini, prototype yang telah dirancang akan dievaluasi. Tahap ini akan terus menerus diulang sampai aplikasi cukup sesuai dengan keinginan. Apabila prototype telah selesai, maka tahapan aplikasi akan kembali berlanjut ketahap design. Gambar 1 menjelaskan bagaimana urutan proses pengembangan perangkat lunak dengan model prototype.

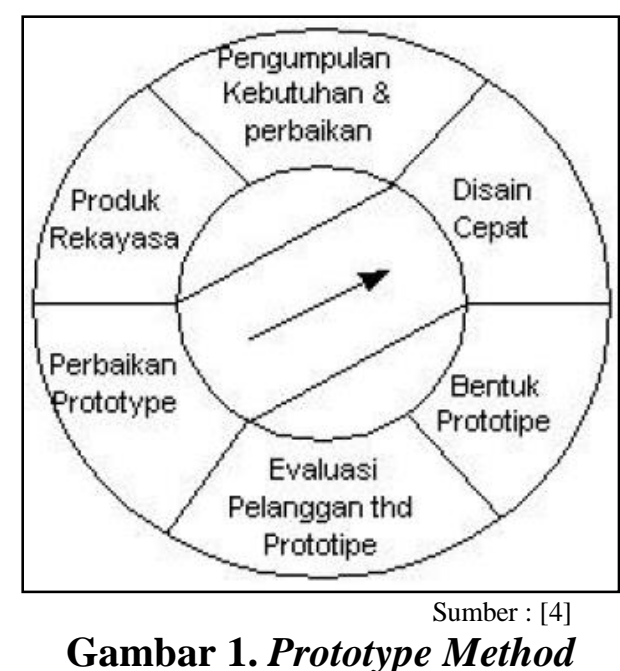

Tahapan penelitian dalam pembuatan program disajikan sebagai berikut:
a. Studi
literature
dengan
mengumpulkan referensi yang
dibutuhkan untuk membangun sistem dari berbagai sumber.

b. Metode Observasi dengan melihat dan menghimpun data-data yang dibutuhkan terkait permasalahan yang dihadapi.

c. Analisa dan perancangan terhadap sistem yang akan dibangun, seperti desain sistem, aturan sistem, pengolahan data, dan laporan.

d.Pembuatan Aplikasi dilakukan lalu diimpelementasikan, sehingga menjadi sebuah sistem dengan dasar bantuan literature yang sudah di kumpulkan sebelumnya.

e. Ujicoba merupakan sangat penting karena pada tahap ini aplikasi di jalankan dan dilihat apakah ada yang kurang ataupun salah, dan tidak sesuai konsep yang dilakukan. 


\section{HASIL DAN PEMBAHASAN}

Hasil dari penelitian ini dipandang dari manfaat aplikasi pendetaksi perkembangan anak dan balita telah dibuat. Kebutuhan pelayanan informasi dalam mendeteksi permasalahan pada perkembangan anak dan balita dikalangan pencari informasi. Dengan system yang ada pada saat ini dimungkinkan terjadinya banyak kesalahan terutama dalam hal membuat laporan data karena kelalaian manusia serta banyaknya tumpukan kertas laporan yang hilang, sehingga perlu dibuat sistem baru yang dapat mengatasi masalah tersebut.

Tahapan pembuatan aplikasi terbagi dalam beberapa bagian perancangan sistem adalah sebagai berikut:

a. Perancangan database secara konseptual terdiri atas tiga langkah berikut ini:

1) Pembuatan entitas

2) Pendefinisian hubungan antar entitas.

3) Penerjemahan hubungan antar entitas.

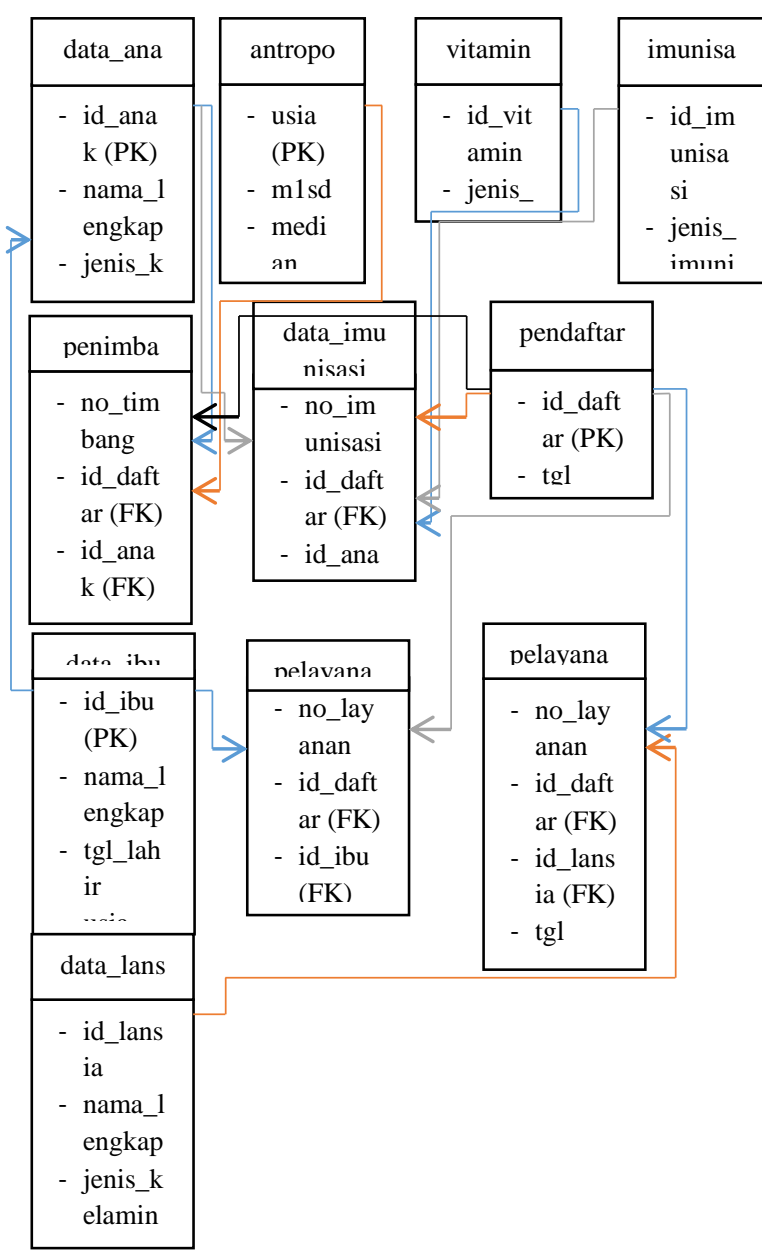

Sumber : Penulis., 2019

\section{Gambar 2. Skema Dan Relasi Table} Database

b. Perancangan Data Flow Diagram, terdiri dari notasi penyimpinan data (data store), proses (process), aliran data (flow data), dan sumber masukan (entity). DFD menggambarkan subsistem dan aliran data dalam sistem, suatu representasi grafik dari suatu sistem yang menggambarkan komponen dari suatu tujuan dan penyimpanan data [6].

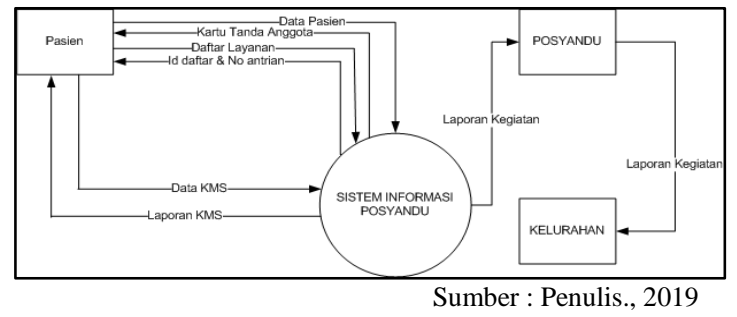

Gambar 3. Diagram Konteks 


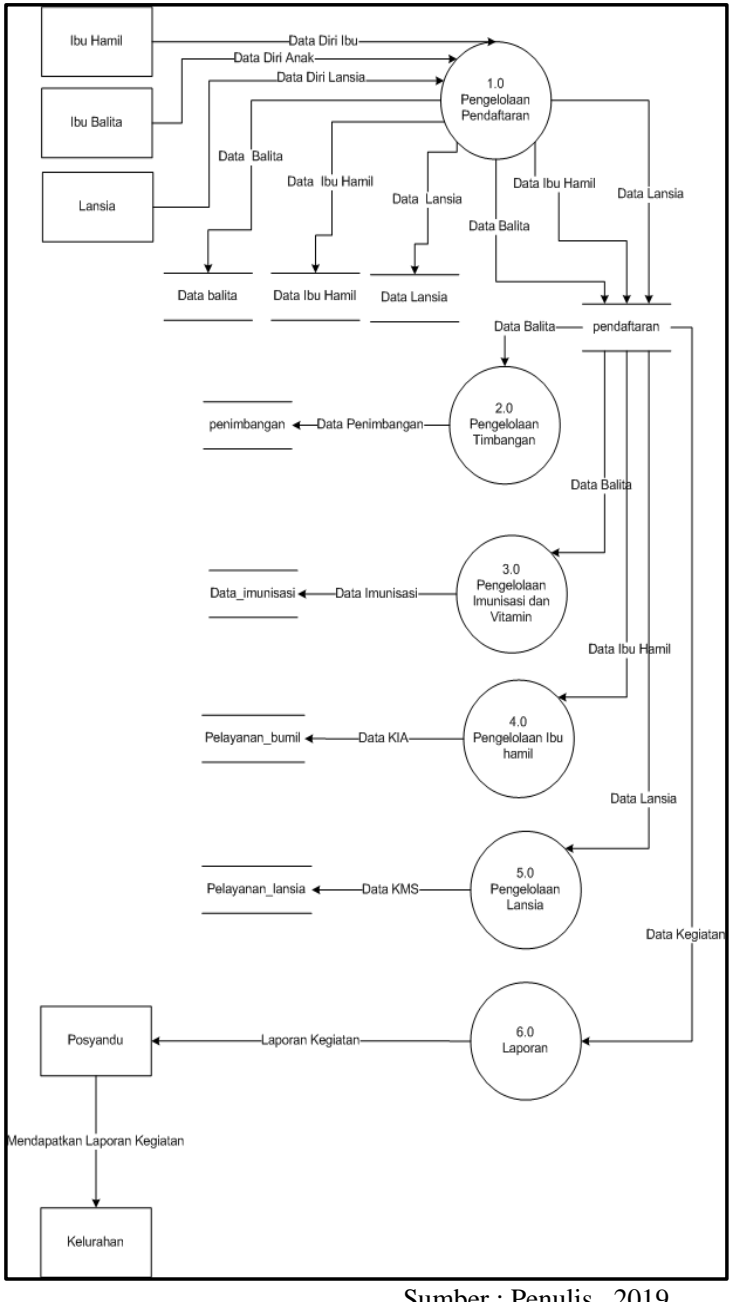

Gambar 4. Diagram Nol

Perancangan sistem aplikasi digunakan untuk menerjemahkan perancangan sistem database yang dibuat sampai dengan eksekusi dari aplikasi yang dibuat. Perancangan sistem program aplikasi ini terdiri dari beberapa langkah sebagai berikut:

a. Pengkodean program aplikasi

b. Eksekusi program aplikasi

c. Cara kerja Program

Tampilan layar antar muka pada Posyandu Bougenvile Depok seperti dibawah ini:

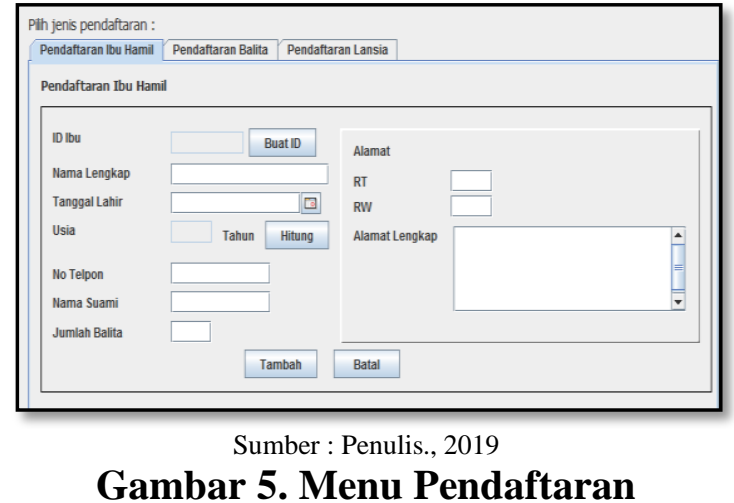

Pada tampilan menu pendaftaran, user dapat memilih jenis pendaftaran meliputi: pendaftaran ibu hamil dan pendaftaran balita, setelah itu menekan tombol tambah untuk mengetahui jenis pelayanan yang di pilih. Apabila user tidak memilih satupun masalah maka pelayanan tidak akan dapat didata oleh sistem.

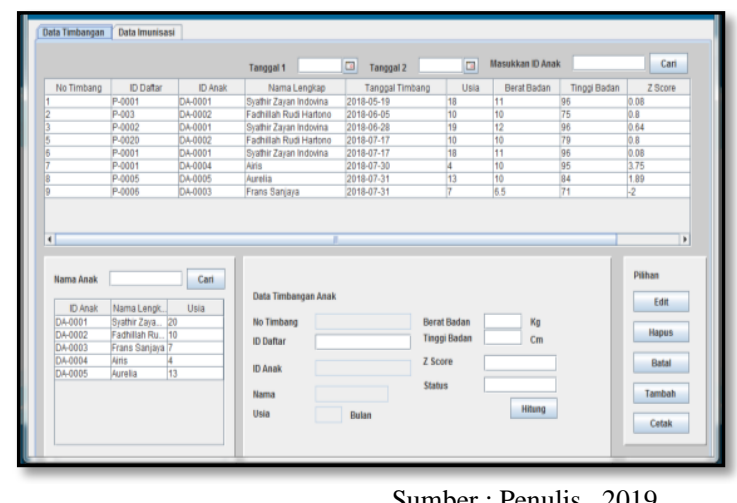

Gambar 6. Menu Pelayanan Balita

Pada tampilan menu pelayanan balita, user dapat mengetahui kondisi balita dengan melihat data timbangan dan data imunisasi.

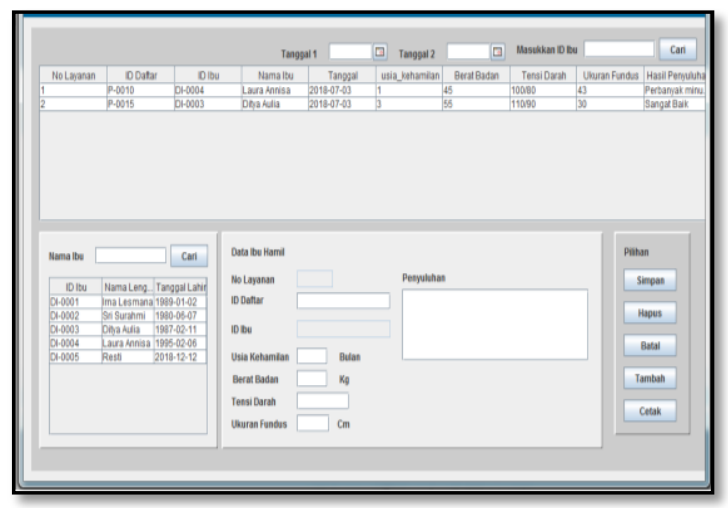

Sumber : Penulis., 2019

Gambar 7. Menu Pelayanan Ibu Hamil 
Pada menu pelayanan ibu hamil, user dapat mengetahui kondisi perkembangan ibu hamil melalui hasil pencatatan meliputi: usia kehamilan, berat badan, tensi darah, dan ukuran fundus.

\section{SIMPULAN}

Dari hasil penyajian data di atas dapat disimpulkan bahwa dengan dibangunnya Perancangan Sistem Aplikasi Pengolahan Data Balita Posyandu Bougenvile pada warga Depok Berbasis Java dapat membantu dan mempermudah dalam pengolahan data laporan kegiatan di dalam Posyandu Bougenvile. Dengan adanya sistem yang berbasis komputerisasi, diharapakan proses laporan kegiatan Posyandu menjadi lebih efektif, menghasilkan input dan output yang lebih cepat dan mengurangi kesalahan dalam pelaporan, sehingga kegiatan-kegiatan yang berkaitan dengan pelayanan berjalan lebih efektif.

\section{DAFTAR PUSTAKA}

[1] Markum, A.H. Ilmu Kesehatan Anak. Jakarta: Fakultas Kedokeran Universitas Indonesia.1996.

[2] Indrajani. Bedah Kilat 1 Jam Pengantar dan Sitem Basis Data. Jakarta: PT. Media Elex Media Komputindo. 2014.

[3] Fadlyana. Konsep Umum Tumbuh Kembang Anak dan Deteksi Dini Penyimpangan Pertumbuhan. Bandung: Makalah dalam Workshop Deteksi Dini dan Pemantauan Tumbuh Kembang. 2006.

[4] Roger, S. Pressman, Ph.D. Rekayasa Perangkat Lunak (Pendekatan Praktisi) Edisi 7 Buku 1. Yogyakarta: Andi. 2012.

[5] Soetjiningsih. Tumbuh Kembang Anak. Jakarta: Penerbit EGC. 1995.

[6] Yakub, Pengantar Sistem Informasi. Yogyakarta: Graha Ilmu. 2012. 